CASES

\title{
Leukemia cutis: an unusual rash in a child
}

\author{
Aarathi Sambasivan MD, Kathryn Keely MD, Karen Mandel MD, Donna L. Johnston MD
}

Previously published at www.cmaj.ca

$\mathrm{A}$ previously healthy four-year-old girl presented with a rash of sudden onset consisting of erythematous macules on both cheeks (Figure 1) that were neither itchy nor tender and did not blanch. Over the next week, the rash spread from her cheeks to her arms, back, thighs and buttocks, and became papular and darker. The patient had no other symptoms. One week later, when the rash had not resolved, oral cephalexin was prescribed. The rash did not improve and the patient was referred to a pediatric dermatologist.

A skin biopsy performed two weeks after the onset of the rash showed leukemic blast cells (Figure 2). Bloodwork was then performed and a peripheral blood smear showed blast cells. Physical examination showed hepatosplenomegaly and mild cervical lymphadenopathy in addition to the rash.

A complete blood count showed a leukocyte count of 17.7 (normal 5.0-14.5) $\times 10^{\%} / \mathrm{L}$, a hemoglobin level of 115 (normal 115-135) g/L, a platelet count of 175 (normal 150-450) $\times$ $10 \% / \mathrm{L}$, an absolute neutrophil count of 0.35 (normal $1.5-8.0) \times$ $10^{9} / \mathrm{L}$ and a blast cell count of 16.6 (normal $\left.<0.01\right) \times 10^{9} / \mathrm{L}$. No evidence was found of tumour lysis syndrome. A bone marrow aspirate confirmed $\mathrm{T}$-cell acute lymphoblastic leukemia with $80 \%-85 \%$ blast cells (Figure 3). Immunophenotyping showed that the blast cells were positive for CD45, CD3, CD7, CD5 and DNA nucleotidylexotransferase. They were also weakly positive for CD79a and CD2. Cytogenetic testing showed a structural rearrangement between chromosomes 9 and 12 resulting in the deletion of their short arms $(45, \mathrm{XX},-9, \mathrm{t}(9 ; 12)(\mathrm{q} 12 ; \mathrm{p} 1))$.

The results of a lumbar puncture showed no evidence of

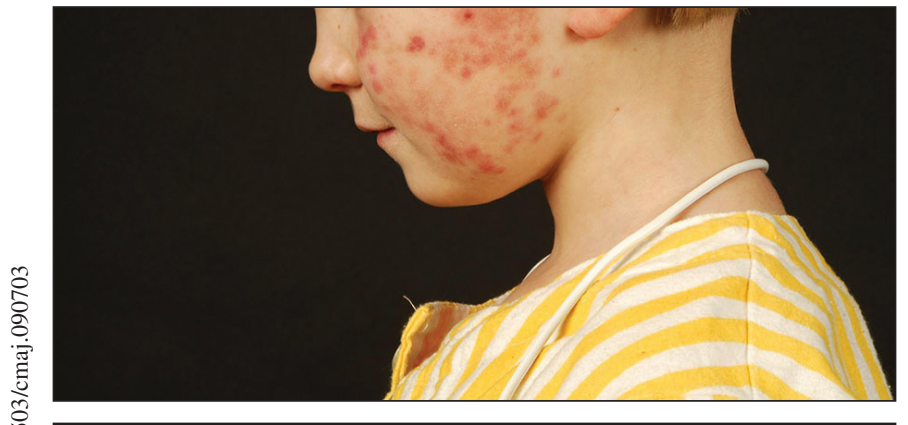

Figure 1: Erythematous macular-papular rash on the cheek of a four-year-old girl with leukemia cutis.

\section{Key points}

- A sudden, persistent rash of unknown cause warrants full physical examination, hematologic investigation including complete blood count, and dermatological evaluation.

- Childhood leukemia may present directly on the skin, a condition known as leukemia cutis.

- Leukemia cutis is seen more commonly in acute myelogenous leukemia than in acute lymphoblastic leukemia.

- The rash generally resolves with treatment of the underlying leukemia.

leukemic cells. A radiograph of the chest was normal. Ultrasonography of the abdomen confirmed hepatosplenomegaly with extension of the edge of the liver to $3 \mathrm{~cm}$ below the costal margin and enlargement of the spleen to a diameter of $13.9 \mathrm{~cm}$.

Induction therapy was started immediately, using protocol COG AALL 0434, which includes intrathecal methotrexate, intrathecal cytarabine, vincristine, prednisone, peg-asparaginase and daunorubicin. At the end of induction, the patient's bone marrow contained $26 \%$ blast cells. Remission was achieved during the consolidation phase using nelarabine, cyclophosphamide, cytarabine, mercaptopurine, vincristine, peg-asparginase and intrathecal methotrexate. No complications occurred from the chemotherapy. The rash resolved midway through induction chemotherapy without scarring or residual pigmentation.

\section{Discussion}

Acute lymphoblastic leukemia is the most common leukemia of childhood. It commonly presents with nonspecific symptoms, such as fatigue and irritability, along with symptoms secondary to bone marrow failure. In pediatric acute lymphoblastic leukemia, $48 \%$ of patients will have petechiae or purpura on presentation. ${ }^{1}$ Occasionally, leukemia can present

From the Department of Pediatrics (Sambasivan, Keely, Mandel, Johnston) the Division of Community Pediatrics (Keely) and the Division of Hematology-Oncology (Mandel, Johnston), Children's Hospital of Eastern Ontario, Ottawa, Ont.

CMAJ 2009. DOI:10.1503/cmaj.090703 


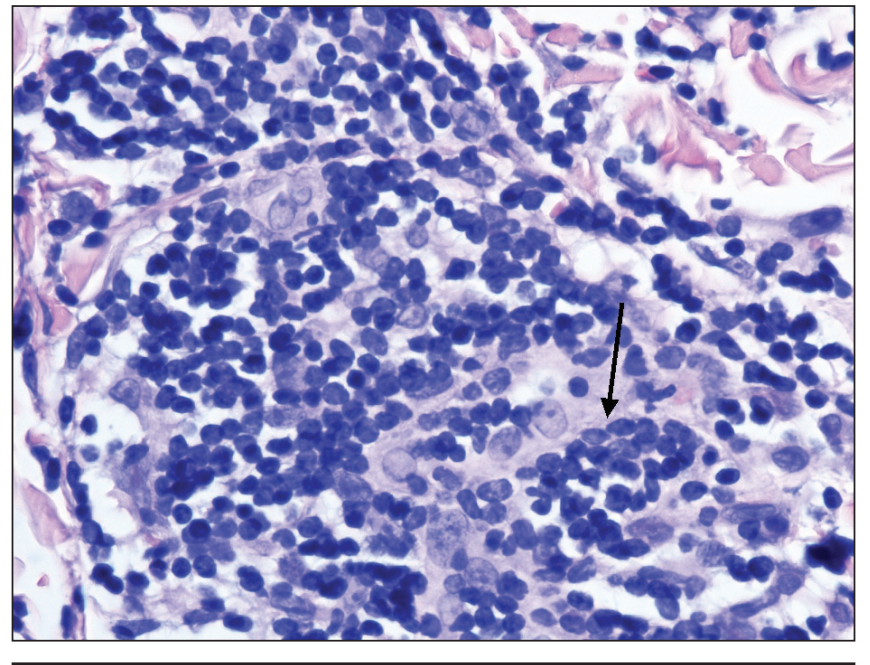

Figure 2: Microscopic view of skin biopsy specimen (hematoxylin and eosin stain, original magnification $\times 600$, ) showing leukemic blast cells (arrow).

directly in the skin and is referred to as leukemia cutis. Although leukemia cutis tends to present with other features of leukemia, it can occasionally precede the development of blast cells in the marrow and blood. ${ }^{1}$ The condition is then known as aleukemic leukemia cutis. ${ }^{1,2}$

Leukemia cutis is an infiltration of the skin by neoplastic leukocytes (myeloid or lymphoid), resulting in clinically identifiable cutaneous lesions. ${ }^{3}$ It is seen most commonly in congenital leukemia and acute myelogenous leukemia. ${ }^{3}$ In adults with acute myelogenous leukemia, leukemia cutis represents a higher tumour burden and tends to be predictive of a prolonged and less favourable course. ${ }^{4}$ These tendencies do not

Table 1: Differential diagnosis of leukemia cutis

\begin{tabular}{|c|c|}
\hline Condition & Characteristics \\
\hline Petechiae or purpura & $\begin{array}{l}\text { Darkly coloured; erythematous; } \\
\text { violaceous; lesions do not blanch } \\
\text { with pressure; associated with low } \\
\text { platelets }\end{array}$ \\
\hline Adverse drug reaction & $\begin{array}{l}\text { Associated with medication; often } \\
\text { maculopapular or urticarial with } \\
\text { systemic symptoms }\end{array}$ \\
\hline Infection & $\begin{array}{l}\text { Redness usually occurs; associated } \\
\text { with fever; may be variable in } \\
\text { presentation }\end{array}$ \\
\hline $\begin{array}{l}\text { Cutaneous lymphoma } \\
\text { (mycosis fungoides or } \\
\text { Sézary syndrome) }\end{array}$ & $\begin{array}{l}\text { Lesions are hypopigmented in } \\
\text { pediatric mycosis fungoides } \\
\text { whereas adults have erythematous } \\
\text { patches and plaques. Sézary } \\
\text { syndrome presents with diffuse } \\
\text { erythroderma and } \\
\text { lymphadenopathy. }\end{array}$ \\
\hline Leukemia cutis & $\begin{array}{l}\text { Erythematous or violaceous } \\
\text { plaques, papules or nodules } \\
\text { occurring most commonly on the } \\
\text { face, trunk or extremities; may be } \\
\text { variable in presentation }\end{array}$ \\
\hline
\end{tabular}

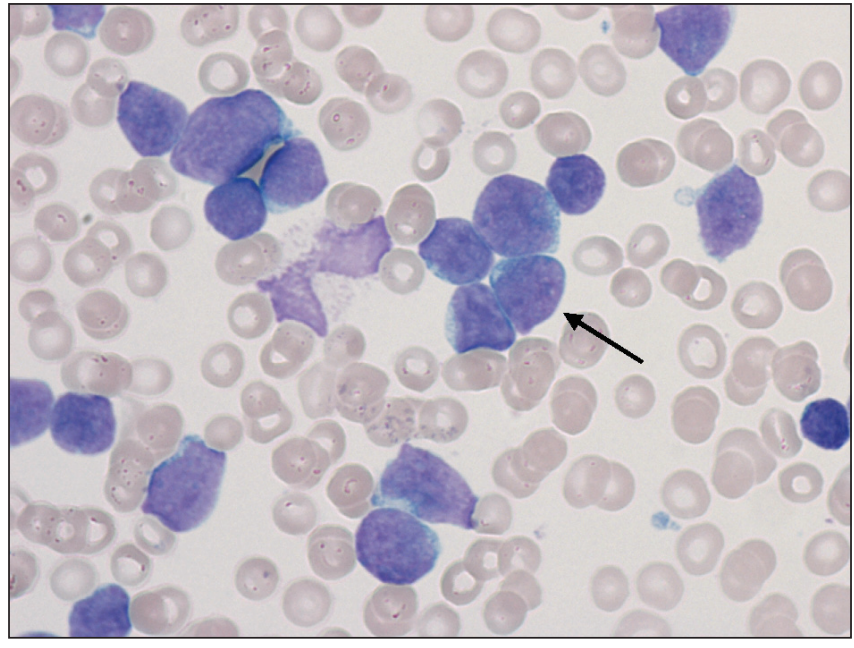

Figure 3: Histologic image of bone marrow aspirate (Wright Giemsa stain, original magnification $\times 1000$, ) showing multiple lymphoblasts (arrow).

seem to be the case in congenital leukemia, where the presence of this rash does not alter the expected course. ${ }^{5}$ In the pediatric population, the frequency of leukemia cutis is higher in pediatric acute myelogenous leukemia (approximately 10\%) than in pediatric acute lymphoblastic leukemia $(1 \%))^{1,2}$

The clinical appearance of leukemia cutis is variable. The most common manifestation is described as erythematous or violaceous plaques, papules or nodules involving the face, trunk and extremities. ${ }^{4}$ Less common appearances include macules, maculopapules or plaques. ${ }^{4}$ In the setting of acute myelogenous leukemia, leukemia cutis presents as a firm nodule with a greenish hue, known as a chloroma or granulocytic sarcoma. ${ }^{1}$ In the neonate, leukemia cutis often presents as sites of extramedullary hematopoiesis in the skin, imparting a "blueberry muffin" appearance. ${ }^{5}$ In our patient, the appearance of leukemia cutis was typical.

\section{Differential diagnosis}

Leukemia cutis needs to be differentiated from cutaneous manifestations of leukemia secondary to bone marrow dysfunction (such as petechiae), drug reactions and infections secondary to an immunocompromised state (Table 1).

Leukemia cutis must also be distinguished from the cutaneous lymphomas (i.e., mycosis fungoides and Sézary syndrome). ${ }^{1,3}$ Children with mycosis fungoides tend to have hypopigmented lesions, especially on the buttocks. ${ }^{1}$ Sézary syndrome is a cutaneous lymphoma that presents as diffuse erythroderma and lymphadenopathy; it involves the blood, skin and lymph nodes. ${ }^{3}$ The syndrome is similar to mycosis fungoides but has a more aggressive course. ${ }^{3}$ Cutaneous lymphomas are very uncommon in the pediatric population.

In our patient, leukemia cutis was the only presenting symptom of T-cell acute lymphoblastic leukemia. This instance of the disease shows that sudden rashes, if persistent and of unknown cause, warrant a full physical examination to look for other abnormalities. Complete evaluation of this type of rash 
should include bloodwork with a complete blood count, imaging as indicated and early involvement of a dermatologist.

This article has been peer reviewed.

\section{Competing interests: None declared.}

Contributors: All of the authors contributed to the development of the concepts in the manuscript and to the drafting and revision of the manuscript. All of them approved the final version submitted for publication.

Acknowledgements: The authors would like to thank Dr. E. Leung and Dr. R. Prokopetz for providing microscopic photographs.

\section{REFERENCES}

1. Pizzo PA, Poplack DG, editors. Principles and practice of pediatric oncology. Philadelphia (PA): Lippincott Williams \& Wilkins; 2006.

2. Millot F, Robert A, Bertrand Y, et al. Cutaneous involvement in children with acute lymphoblastic leukemia or lymphoblastic lymphoma. Pediatrics 1997;100:60-4.

3. Cho-Vega JH, Medeiros LJ, Prieto VG, et al. Leukemia cutis. Am J Clin Pathol 2008;129:130-42.

4. Longacre TA, Smoller BR. Leukemia cutis. Analysis of 50 biopsy-proven cases with an emphasis on occurrence in myelodysplastic syndromes. Am J Clin Pathol 1993;100:276-84.
5. Resnik KS, Brod BB. Leukemia cutis in congenital leukemia. Analysis and review of the world literature with report of an additional case. Arch Dermatol 1993;129:1301-6.

Correspondence to: Dr. Donna Johnston, Children's Hospital of Eastern Ontario, 401 Smyth Rd., Ottawa ON K1H 8L1;

djohnston@cheo.on.ca

The section Cases presents brief case reports that convey clear, practical lessons. Preference is given to common presentations of important rare conditions, and important unusual presentations of common problems. Articles start with a case presentation (500 words maximum), and a discussion of the underlying condition follows (1000 words maximum). Generally, up to five references are permitted and visual elements (e.g., tables of the differential diagnosis, clinical features or diagnostic approach) are encouraged. Written consent from patients for publication of their story is a necessity and should accompany submissions. See information for authors at www.cmaj.ca.

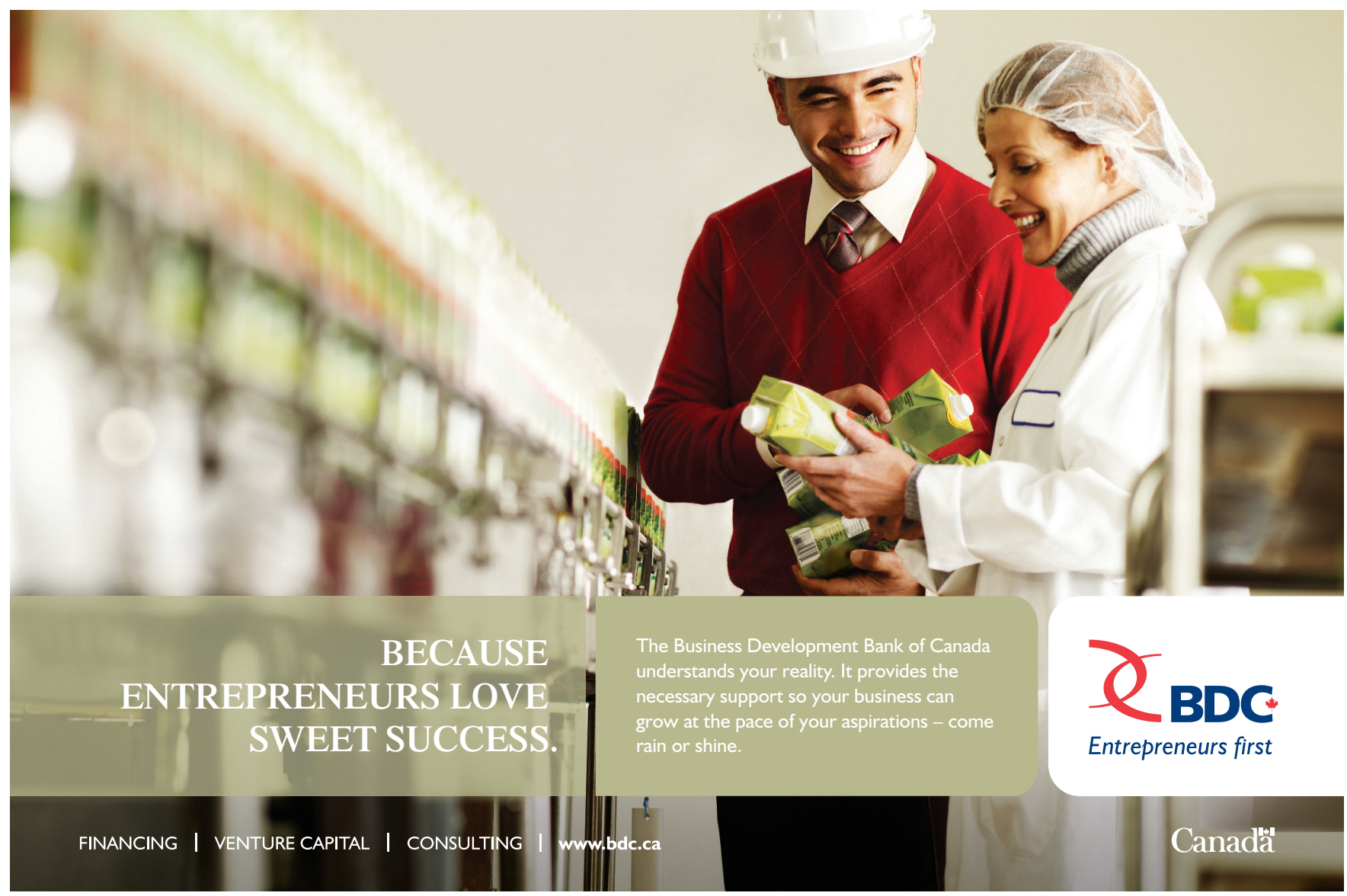

